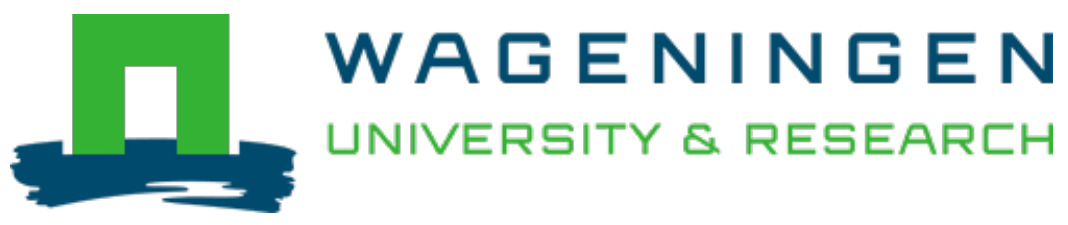

\title{
Principles, drivers and opportunities of a circular bioeconomy
}

Nature Food

Muscat, Abigail; Olde, Evelien M.; Ripoll-Bosch, Raimon; Zanten, Hannah H.E.; Metze, Tamara A.P. et al https://doi.org/10.1038/s43016-021-00340-7

This article is made publicly available in the institutional repository of Wageningen University and Research, under the terms of article $25 \mathrm{fa}$ of the Dutch Copyright Act, also known as the Amendment Taverne. This has been done with explicit consent by the author.

Article 25 fa states that the author of a short scientific work funded either wholly or partially by Dutch public funds is entitled to make that work publicly available for no consideration following a reasonable period of time after the work was first published, provided that clear reference is made to the source of the first publication of the work.

This publication is distributed under The Association of Universities in the Netherlands (VSNU) 'Article $25 \mathrm{fa}$ implementation' project. In this project research outputs of researchers employed by Dutch Universities that comply with the legal requirements of Article $25 \mathrm{fa}$ of the Dutch Copyright Act are distributed online and free of cost or other barriers in institutional repositories. Research outputs are distributed six months after their first online publication in the original published version and with proper attribution to the source of the original publication.

You are permitted to download and use the publication for personal purposes. All rights remain with the author(s) and / or copyright owner(s) of this work. Any use of the publication or parts of it other than authorised under article $25 \mathrm{fa}$ of the Dutch Copyright act is prohibited. Wageningen University \& Research and the author(s) of this publication shall not be held responsible or liable for any damages resulting from your (re)use of this publication.

For questions regarding the public availability of this article please contact openscience.library@,wur.nl 


\title{
Principles, drivers and opportunities of a circular bioeconomy
}

\author{
Abigail Muscat $\mathbb{1}^{1}$, Evelien M. de Olde', Raimon Ripoll-Bosch ${ }^{1}{ }^{1}$, Hannah H. E. Van Zanten ${ }^{2}$, \\ Tamara A. P. Metze ${ }^{3}$, Catrien J. A. M. Termeer ${ }^{3}$, Martin K. van Ittersum ${ }^{4}{ }^{4}$ and Imke J. M. de Boer ${ }^{1 凶}$ \\ A circular, bio-based economy could provide the pathway to a sustainable future. Here we present five ecological principles to \\ guide biomass use towards a circular bioeconomy: safeguarding and regenerating the health of our (agro)ecosystems; avoiding \\ non-essential products and the waste of essential ones; prioritizing biomass streams for basic human needs; utilizing and recy- \\ cling by-products of (agro)ecosystems; and using renewable energy while minimizing overall energy use. Implementing these \\ principles calls for a transformation of our current economic system, including fundamental changes to policies, technologies, \\ organizations, social behaviour and markets.
}

iomass is the basis of our food system and future bioeconomy. To produce food, feed and biomaterials such as fibre, biochemicals, bioplastics and bioenergy, humans harvest biomass from agroecosystems (for example, managed arable and grasslands) as well as natural ecosystems (for example, natural waters or forests) (Fig. 1).

More biomass has been harvested over the past century than ever before $^{1,2}$, often leading to land-use change, biodiversity loss, climate change, water pollution and land degradation. These problems are likely to worsen as demand for biomass rises due to population growth and diets become richer in animal-sourced foods ${ }^{3}$.

The need to transform the economy to avoid exceeding the Earth's biophysical limit is widely recognized ${ }^{4}$ and a circular bioeconomy is one of the ways to achieve this. An integrated framework that places biomass utilization in a wider context and prioritizes its use for basic human needs is still missing. Addressing this gap is crucial given the potential competition for biomass between different uses ${ }^{5}$.

Here we propose five principles for circular biomass use based on the concept of circularity and its roots in disciplines such as industrial ecology, ecological economics, agroecology and general systems theory. We also identify institutional, technological, organizational, behavioural, cultural and market drivers (able to accelerate change) and opportunities (or key leverage points) needed to implement the five key ecological principles.

\section{Principles for circular biomass use}

Acknowledging that a single definition for circular bioeconomy might not exist ${ }^{6}$, we argue that a circular bioeconomy ought to minimize the depletion of resources (for example, phosphate rock, fossil fuels or soils), encourage regenerative practices (for example, restoring fish stocks), prevent the loss of natural resources (for example, carbon, nutrients and water) and stimulate the reuse and recycling of inevitable by-products, losses or wastes in a way that adds the highest possible value to the system.

A circular bioeconomy is inherently limited by the biosphere with its natural cycles and sinks. Here, we focus on (agro)ecosystems of biomass production, encompassing land-based agriculture, fisheries and aquaculture, as well as natural and managed ecosystems (Fig. 1).

Safeguard. Biomass production requires healthy aquatic, arable, grassland and forest (agro)ecosystems. To safeguard the health of these systems, farming, fishing and forestry practices must utilize natural resources at a rate that does not exceed their regenerative and absorptive capacity, to ensure current and future availability of natural resources.

Thus, the first principle calls for production practices that contribute to the conservation and regeneration of the health of (agro) ecosystems and the resources they provide. The safeguard principle also implies minimizing - and ideally halting - the consumption of finite resources (such as phosphate rock or fossil fuels) and stimulating the use of regenerative ones (such as solar and wind energy). More than a simple reduction of throughput flows of natural resources, this principle also implies continuous regeneration of resource quality. To sustain biomass harvesting from agroecosystems, for example, we need to invest in restoring soil carbon stocks. In the absence of technologies and strategies that reduce greenhouse gas (GHG) emissions or reduce the absorptive capacity of ecosystems (for example, carbon capture and storage systems can act as artificial sinks), a circular bioeconomy means a greater dependency on the speed of natural cycles.

Not exceeding the absorptive capacity means that waste or losses are generated at a lower rate than the assimilation capacity of (agro) ecosystems. For instance, GHG emissions should not exceed these systems' sink capacity. Forests, for example, can act as a carbon sink as well as a valuable source for paper and pulp, textile or bioenergy industries. The capacity of (agro)ecosystems to act as sinks should be protected and enhanced, acknowledging that agroecological conditions and sink capacity differ across geographical scales.

Biodiversity plays an essential role in providing a variety of buffering capacities ${ }^{7}$ and contributing to present and future ecosystems' resilience. Protecting biodiversity requires conserving the natural ecosystems that are left (for example, zero deforestation targets) and regenerating or restoring degraded ones (for example, regenerate

'Animal Production Systems group, Wageningen University \& Research, Wageningen, The Netherlands. ${ }^{2}$ Farming Systems Ecology group, Wageningen University \& Research, Wageningen, The Netherlands. ${ }^{3}$ Public Administration and Policy group, Wageningen University \& Research, Wageningen, The Netherlands. ${ }^{4}$ Plant Production Systems group, Wageningen University \& Research, Wageningen, The Netherlands. e-mail: abigail.muscat@wur.nl 


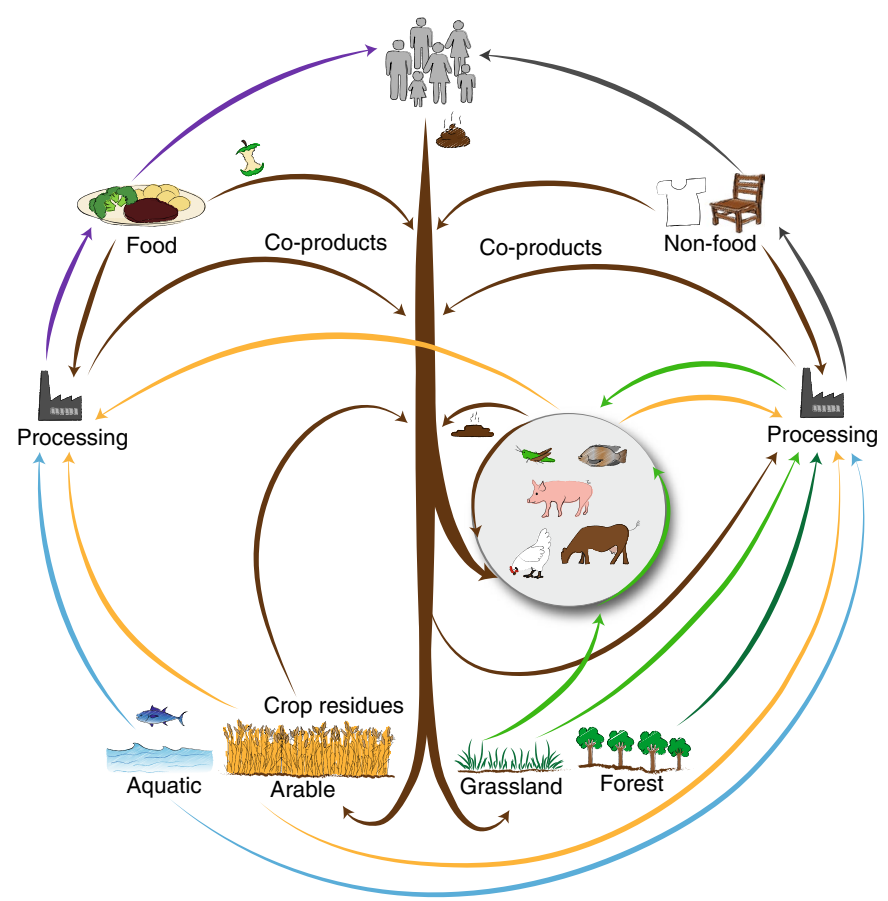

Fig. 1 | Biomass flows in a circular bioeconomy. Biomass from aquatic, arable, grassland and forest production systems are processed or consumed. By-products and wastes are recycled back into the system.

soil health, encourage biodiversity-enhancing practices such as diverse crop rotations).

Avoid. The second principle addresses the use and production of non-essential bio-based products and the avoidance of losses and waste of essential ones. Avoiding non-essentials can prevent unnecessary exploitation of natural resources ${ }^{8}$, especially as impacts of production are unlikely to be fully offset by recovery and recycling. Moreover, emissions to air, water and soil ${ }^{9,10}$ can be avoided by preventing the impact of production processes further upstream.

A question then arises: what are essential and non-essential products and what is waste? Despite food being essential, we waste one-third of all food globally each year and discard a third of the global fisheries catch for not being the target species ${ }^{11}$. These estimates do not include overconsumption ${ }^{12}$. In countries of high-to-middle income, an average person's intake of calories is higher than needed, resulting in more deaths linked to obesity than underweight ${ }^{13}$. One may also question the value of ultra-processed foods with their low nutritional value and negative impact on health ${ }^{14,15}$. In sectors other than food, such as clothing and electronics, waste is generated at a rapid pace as the lifetime of products has greatly reduced. The rise of 'fast fashion' has reduced the average lifespan of a garment to around three years ${ }^{16}$. Determining which products are essential or non-essential and what is waste rather than a by-product entails challenging questions and requires the engagement of different sectors of society.

Prioritize. With growing biomass demands, natural resources need to be used effectively. The third principle refers to the priorities in the use of biomass. We argue that priority should start with basic human needs (food, pharmaceuticals, clothes) and sectors without sustainable alternatives (such as the chemical industry). This implies, for instance, avoiding bioenergy use for light road vehicles since better alternatives exist (for example, electrification). Bioenergy could be used in aviation, heavy transport and shipping until technologically and economically viable alternatives arise.
Currently, biomass is not effectively used to meet food requirements. About $40 \%$ of global arable lands are used to produce high-quality feed for livestock, much of which is human-edible ${ }^{17}$. Similarly, most fish that end up in fishmeal could be consumed by humans ${ }^{18}$. Direct human consumption of such feeds would be more resource-efficient ${ }^{19,20}$. However, livestock and farmed fish can contribute significantly to a sustainable nutrient supply, especially highly bio-available ones (such as protein and iron) or nutrients largely absent in plant-sourced food (such as vitamin B12 and long-chain essential fatty acids ${ }^{21,22}$ ).

Following the prioritize principle, these livestock and fish would only consume leftovers from arable land or fisheries and grass resources (recycle principle); that is, human-inedible biomass. Future biorefineries might also upgrade inedible biomass streams such as cultivated grass into proteins that humans can eat. People can also consume a larger diversity of aquatic foods from aquatic production systems, each in proportion to its natural production capacity ${ }^{23}$ (safeguard principle).

Biomass is also required for essential non-food biomaterials such as clothing. Availability and resource use efficiency can be maximized through the biomass cascading principle ${ }^{24}$, and biomass can be used multiple times before being converted to energy. Directing biomass towards material rather than energy uses may sequester carbon for longer periods of time $\mathrm{e}^{25}$ and prevent the need for additional biomass harvest. Here we argue for prioritizing non-food materials such as furniture and housing ${ }^{26}$ that also sequester carbon if used sustainably.

For cascades to work, incentivizing the use of biomass for creating materials instead of producing bioenergy will be needed across countries. Such cascades can be directed by social norms. We propose that biomass cascades are best informed by frameworks of human needs ${ }^{27,28}$ and resource use efficiency rather than the economics that is leading to current cascade frameworks such as the value pyramid $^{29}$. The production of bioenergy, for instance, is then only desirable or effective for biomass streams that are not safe for recycling, such as waste streams containing human and veterinary pharmaceuticals. Just as with the prioritize principle, reframing biomass cascades will entail rethinking which products are essential for human development.

Recycle. Even if the waste of food and non-food bioproducts is avoided, the production and consumption of essential food and non-food bio-based products result in by-products, such as manure and slaughterhouse waste from animal production. Our fourth principle calls for nutrients and carbon from by-products to be recycled back into the bio-based system, prioritizing human and planetary well-being.

Based on the avoid principle, the priority is avoiding human-edible by-products, such as the middlings from white and brown bread. Inevitable by-products, such as straw or animal/ human excreta, do contain valuable nutrients and carbon. Recycling them into (agro)ecological systems (Fig. 1) can enrich the soil, fertilize crops, feed farm animals and produce biomaterials. Recycling implies, for example, reconnecting arable and livestock farming at farm and regional scales, but also building new connections between, for example, cities and their hinterlands.

We have to ensure that by-products are safe to recycle and do not cause harmful effects to humans, animals or the environment. For example, while plant-based human-inedible food waste can be immediately fed to farm animals, animal-contaminated food waste must be heat-treated to deactivate potential diseases before being fed to pigs, poultry, fish and insects. That said, recycling may entail a trade-off between food safety and additional energy and transport ${ }^{30}$.

Entropy. The driving force behind the recycling of nutrients and carbon in (agro)ecosystems is energy. While biogeochemicals, such 
as nutrients and carbon, are cycled through ecosystems, energy flows and cascades from useful to less useful forms of energy ${ }^{31}$ as during each energy transformation process, entropy, or disorder, increases. Increased circularity and recycling costs energy and a fully circular bioeconomy is difficult to achieve given the losses in each consecutive $c y c l e^{31,32}$. The fifth principle advocates minimizing energy use by working with nature, moving towards renewables and efficiently utilizing the rare metals on which current renewable technologies depend.

Following ecological engineering and design principles, a system can maximize the use of free-flowing energy from natural sourcesparticularly the Sun. Examples of energy systems that 'work with nature' and thereby minimize overall energy use include silvopastoral farming systems or multispecies aquaculture; both illustrate how it is better to conserve energy in ecosystems by prioritizing material uses over energy use (via the principle of cascading) than to increase the use of biomass for bioenergy ${ }^{33}$.

Given the above, as well as the need to move away from fossil fuels, the future circular bioeconomy will need to be based on renewable energy. Current technologies depend on finite metals and minerals to produce solar panels or wind turbines ${ }^{34}$, underscoring the need to ensure that finite non-renewable materials (for example, lithium and cobalt) can be recycled more easily in the future ${ }^{35,36}$.

\section{Drivers and opportunities for a circular bioeconomy}

Policies. A clear opportunity for promoting a circular bioeconomy lies in creating synergies between different policy domains (circular economy, climate, agriculture, energy, and industrial policy). An integrative perspective is required as biomass is produced and used by many different economic sectors-and, therefore, governed by different policy domains at different stages of the supply chain. This currently creates incoherencies, trade-offs and even conflicting claims on biomass. For instance, non-food biomass in the EU is directed towards energy first due to renewable energy policies despite cascading principles being in place that favour material uses first ${ }^{37,38}$. Following the prioritize principle, resource-efficient cascading can be applied to all biomass while removing distorted policy incentives.

Policies that promote circularity, such as interventions to reduce animal-source food consumption (for example, taxation) or feeding livestock with potentially health-hazardous animal-contaminated food wastes, may have limited support. It is, therefore, crucial to determine which policy measures are more effective by aiming for stronger 'leverage' points that go beyond isolated fixes; this requires taking into account societal acceptance and system-based legislative frameworks, and avoiding vicious cycles that inhibit transformative change ${ }^{39}$.

Clearly, change is also necessary within the governance system. Circularity can be achieved with systems thinking that combines top-down and bottom-up approaches ${ }^{40}$, allowing for adaptation and learning, and protecting against undesirable consequences. Policy will also require a vision to balance transformative incentives with reliable performance. Funding for innovation will enable farmers, foresters, fisherfolk and other (agro)ecosystem managers to benefit from the circular bio-based economy.

Technologies. Key drivers for a transition toward a circular bioeconomy are new technologies, as well as the redesign of existing ones. More concretely, opportunities lie in reducing dependency on the speed of natural cycles, either by lowering resource use and emissions or enhancing the absorptive capacity of ecosystems. Examples include carbon capture and storage technologies, plants bred for improved photosynthesis and more effective solar power (see safeguard principle). The redesign of existing technologies and products is necessary for a circular bioeconomy to improve the lifespan, repairability and recyclability of products. Environmental impacts can be greatly reduced if circularity is taken into account at the product design stage ${ }^{41}$. For plant breeding, this may entail designing for optimization of yield and quality of main products and by-products ${ }^{42}$.

Currently, product redesign is inhibited by the widespread obsolescence of products (for example, fast fashion) in combination with a lack of skills, investment and incentives for redesign, product recycling and remanufacturing infrastructure ${ }^{43}$. In addition, many bio-based products are coated or mixed with other materials, such as construction wood, wooden furniture and textiles. This process could be accelerated with open databases of tried and tested bio-based materials as well as information and communication technologies that allow for material tracing across supply chains. Stakeholder dialogue and transparency will be particularly important in assuring the social acceptability of the transition towards circular bioeconomy, which involves discussions on what is considered 'natural' or 'safe' (for example, meat analogues or insects as food and feed).

Organizations. Businesses, non-governmental bodies and other organizations can be key drivers of change through supply chain interventions, organizational culture and access to information. A major barrier, particularly for the bio-based industry, is the inherent heterogeneity and seasonality of biomass, which leads to an unstable and geographically dispersed biomass supply-and possibly biomass degradation. Industries must work together to produce, deliver and process biomass, especially streams such as inedible, unavoidable food waste from the food processing industry, which may be more homogenous than feedstock streams further down the chain, such as consumer waste ${ }^{44}$. Organizational barriers also relate to end-of-life options for bio-based products; safe collection of such products requires adequate labelling, consumer awareness, adequate infrastructure and clear definitions and standards for what is considered biodegradable under specific conditions.

Solutions include moving away from economies of scale, which prioritize increasing specialization, volume and efficiency, to economies of scope, which can exist independently of volume and allow multiple products to be produced together. Economies of scope can create multiple sources of income, lower overall costs ${ }^{44}$ and be combined with multi-product cascading biorefineries, using waste from one process as feedstock for another (prioritize and recycle principles). A network of biorefineries within proximity can create an economy that minimizes waste by avoiding the risk of biomass degradation, overcoming the cost of transport and utilizing waste from nearby production processes ${ }^{44}$.

An economy of scope may involve reconnecting areas where biomass is largely consumed (cities and urban environments) to areas where biomass is produced (rural and agricultural areas). Closing the gap between these could improve circularity by potentially reducing food waste or recycling waste such as human excreta-a rich source of mineral phosphorus that would reduce dependence on phosphate rock ${ }^{9}$. The challenge will be how to address this across geographical scales. Smart technologies to collect, process, transport and safely recycle 'urban nutrients', such as nutrients in human excreta, require further research and investment.

Social behaviour. Research is increasingly recognizing the role of behavioural and cultural factors as drivers of more sustainable behaviour ${ }^{45-47}$ beyond access to information and knowledge about sustainable practices ${ }^{48}$. To meet the safeguard and avoid principles, behavioural and cultural barriers will have to be overcome to shift consumption patterns and keep them within planetary boundaries.

High demands for animal-source food, energy and plastics are often associated with behavioural and cultural factors such as gender and identity ${ }^{49,50}$, as well as psychological biases. For example, a 'psychological distance' bias may be created when plastic waste 
is exported to other countries. This can result in a perception that plastic pollution has been solved, increasing its use $\mathrm{e}^{51}$. What is seen as waste is furthermore culturally and behaviourally mediated ${ }^{52}$ and there is growing recognition that the causes of food waste, particularly at a consumer level, relate to cultural factors such as peer pressure and value-perceptions around waste ${ }^{53,54}$.

Behavioural studies provide many avenues for shifting sustainable behaviour. These can be coupled with formal institutional methods, such as streamlining food labelling ${ }^{55}$ or eco-labels, supermarket ratings and campaigns to normalize sustainable choices. Changing the 'choice environment' may, in particular, be more effective than addressing internal aspects such as values and identity ${ }^{56}$. For example, sub-optimal foods such as 'ugly' fruit and vegetables that end up as food waste can be used in the 'food environment' via changes in retail practices and consumer awareness.

Change is needed at the individual level as well as among communities, culture and society at large. The latter will, however, require a widespread paradigmatic shift. Structural change can be achieved through nudging strategies that alter individual behaviour but can never happen overnight. A strategy of starting with small wins could be more effective ${ }^{57}$. Small wins are in-depth concrete steps at the local level, such as community initiatives and socio-technological innovations (for example, circular community farming). Upscaling, deepening and broadening these circular initiatives can lead to widespread transformations ${ }^{40}$.

Markets. Market incentives can accelerate the shift away from non-circular and fossil-based products and towards bio-based products. However, market barriers currently reduce or block the economic viability of circular products or business models, including barriers to market access and environmentally harmful subsidies that inhibit competition. Investment costs to move from non-renewable to bio-based products are high as competing products (often petrochemical-based) remain cheap compared with their bio-based alternatives due to environmental or social costs being external to prices. Besides, the raw material supply of biomass is uncertain; for example, avoiding waste may ultimately disrupt business plans that rely on waste-biomass as a feedstock. Using food waste and residues from the food processing industry may provide more stable feedstocks.

Some products retain their market value despite not being circular. The cost of virgin biomass materials currently remains low, while the cost of collection of waste biomass remains high. An opportunity for changing this is through market incentives such as taxes on virgin raw materials ${ }^{57}$. For a fair playing field between bio-based and petrochemical products, environmental impacts should be internalized. Furthermore, bio-based alternatives can replace petrochemical products that already have an established market also known as 'drop-ins', which can help overcome the initial barrier of finding a market niche.

\section{Discussion}

Shifting towards a circular bioeconomy requires deep transformations, varying from how we cascade biomass and measure progress to the type of economic development model we pursue as a society. Translating the concept of a circular economy into biomass use requires cascading frameworks that direct biomass towards its highest value to make the most effective use of the limited resources available ${ }^{24}$.

The principles presented here have various implications for existing bioeconomy cascading frameworks for biomass. We suggest that cascading frameworks be informed by human need frameworks accounting for resource use efficiency, implying that 'higher value' is determined by higher need value rather than economic value. Frameworks such as the value pyramid, for example, direct biomass towards higher economic value products such as cosmetics ${ }^{29}$.
Our principles also have implications for circularity concepts such as those of the Ellen MacArthur Foundation ${ }^{58}$, which keep technical and biological cycles separate in theory. In practice, these two cycles are inherently intertwined as they both contain organic and inorganic elements. Complete separation of technical and biological materials is probably unrealistic ${ }^{41}$.

Once the right frameworks are in place, new metrics will be needed to measure progress. Circularity metrics for bio-based products, for example, will have to include levels of harvest of virgin materials and natural resources and require clear definitions of biodegradability and measures of toxicity for end-of-life options ${ }^{59}$. Most importantly, circularity metrics must address the complexity of (agro)ecosystems and their interlinkages, such as feed-foodfuel competition. Metrics must capture resource use efficiency and energy use efficiency from the entire bio-based system, such as the land-use ratio ${ }^{60}$ or measures aimed at the most exergetically efficient energy use (such as combined heating and power systems ${ }^{31,39,61}$ ).

Current product footprints are, by definition, linear metrics, and therefore fall short of addressing the environmental impact of the entire bio-based system. While efforts have been made in system dynamic modelling to better address the interactions between food and non-food uses and capture more of the complexity and non-linearity of bio-based systems ${ }^{62}$, few models to date have incorporated circular principles such as the ones mentioned above.

Besides product-based metrics, system-based metrics are needed to define the maximum level of emissions that can be absorbed by (agro)ecosystems in each region. Such regional ceilings avoid collectively placing an excessive strain on the environment. A transition towards a circular system, therefore, requires a smart combination of metrics at different scales (for example, product, farm and region). This will entail deciding the scale at which recycling should be pursued and nutrient cycles closed ${ }^{63}$. Due to agroecological and socioeconomic conditions, some areas may be more suitable for specific production systems and also outweigh the environmental impact of transport. This, in turn, involves regional considerations about these conditions as much as a discussion on trade and global equity, since achieving increased sustainability in one country may come at the expense of another ${ }^{64,65}$.

While circularity can contribute to all three pillars of sustainability $^{31}$, it mainly addresses staying within planetary boundaries. Yet, a true, sustainable circular bioeconomy requires respect for the social foundation ${ }^{66,67}$. This foundation includes essential rights for humans and animals, such as the right to healthy and safe food, labour protections and farm animals expressing their species-specific behaviour. It also means ensuring farm workers, fisherfolk and land managers-the frontliners of a circular bioeconomy-a prosperous livelihood.

Together, the planetary boundaries and social foundation of our food and bio-based systems should define a safe and just operating space where human, animal and planetary well-being is assured. Transitioning towards this space will require changing the way we value products and services and rethinking our definition of prosperity as we embrace new measures of social progress. It also raises a series of questions about which economic model to pursue and how to monitor its evolution. Although a circular, bio-based economy will require sustained effort to close the loop in our (agro)ecosystems, it could also set humanity on a path towards socio-economic and planetary prosperity.

Received: 10 September 2020; Accepted: 9 July 2021; Published online: 9 August 2021

\section{References}

1. Haberl, H., Erb, K.-H. \& Krausmann, F. Human appropriation of net primary production: patterns, trends, and planetary boundaries. Annu. Rev. Environ. Resour. 39, 363-391 (2014). 
2. Krausmann, F. et al. Global human appropriation of net primary production doubled in the 20th century. Proc. Natl Acad. Sci. USA 110 10324-10329 (2013).

3. Foley, J. A. et al. Solutions for a cultivated planet. Nature 478, 337-342 (2011)

4. Steffen, W. et al. Planetary boundaries: guiding changing planet. Science 347, 1259855 (2015).

5. Muscat, A., de Olde, E. M., de Boer, I. J. M. \& Ripoll-Bosch, R. The battle for biomass: a systematic review of food-feed-fuel competition. Glob. Food Sec. 25, 100330 (2020)

6. Befort, N. Going beyond definitions to understand tensions within the bioeconomy: the contribution of sociotechnical regimes to contested fields. Technol. Forecast. Soc. Change 153, 119923 (2020).

7. Jørgensen, S. E. \& Nielsen, S. N. Application of ecological engineering principles in agriculture. Ecol. Eng. 7, 373-381 (1996).

8. Potting, J., Hekkert, M., Worrell, E. \& Hanemaaijer, A. Circular Economy: Measuring Innovation in the Product Chain (PBL Netherlands Environmental Assessment Agency, 2016).

9. Van Kernebeek, H. R. J., Oosting, S. J., van Ittersum, M. K., Ripoll-Bosch, R. \& de Boer, I. J. M. Closing the phosphorus cycle in a food system: insights from a modelling exercise. Animal 12, 1755-1765 (2018)

10. Scherhaufer, S., Moates, G., Hartikainen, H., Waldron, K. \& Obersteiner, G. Environmental impacts of food waste in Europe. Waste Manag. 77, 98-113 (2018).

11. Global Food Losses and Food Waste: Extent, Causes and Prevention (FAO, 2011).

12. van den Bos Verma, M., de Vreede, L., Achterbosch, T. \& Rutten, M. M Consumers discard a lot more food than widely believed: Estimates of global food waste using an energy gap approach and affluence elasticity of food waste. PLoS ONE 15, e0228369 (2020).

13. Obesity and Overweight. WHO https://www.who.int/news-room/fact-sheets/ detail/obesity-and-overweight (accessed 10 April 2020).

14. Rico-Campà, A. et al. Association between consumption of ultra-processed foods and all cause mortality: SUN prospective cohort study. Brit. Med. J. 365, 11949 (2019).

15. Srour, B. et al. Ultra-processed food intake and risk of cardiovascular disease: prospective cohort study (NutriNet-Santé). Brit. Med. J. 365, 11451 (2019).

16. Daystar, J., Chapman, L., Moore, M., Pires, S. \& Golden, J. Quantifying apparel consumer use behavior in six countries: addressing a data need in life cycle assessment modeling. J. Text. Apparel Technol. Manag. 11, 1-25 (2019).

17. Mottet, A. et al. Livestock: on our plates or eating at our table? A new analysis of the feed/food debate. Glob. Food Sec. 14, 1-8 (2017)

18. Cashion, T., Le Manach, F., Zeller, D. \& Pauly, D. Most fish destined for fishmeal production are food-grade fish. Fish Fish. 18, 837-844 (2017).

19. Garnett, T. Livestock-related greenhouse gas emissions: impacts and options for policy makers. Environ. Sci. Policy 12, 491-503 (2009).

20. Goodland, R. Environmental sustainability in agriculture: diet matters. Ecol. Econ. 23, 189-200 (1997).

21. Van Hal, O. et al. Upcycling food leftovers and grass resources through livestock: impact of livestock system and productivity. J. Clean. Prod. 219 485-496 (2019).

22. Van Zanten, H. H. E. et al. Defining a land boundary for sustainable livestock consumption. Glob. Change Biol. 24, 4185-4194 (2018).

23. Zhou, S. et al. Balanced harvest: concept, policies, evidence, and management implications. Rev. Fish Biol. Fish. 29, 711-733 (2019).

24. Haberl, H. \& Geissler, S. Cascade utilization of biomass: strategies for a more efficient use of a scarce resource. Ecol. Eng. 16, 111-121 (2000).

25. Suominen, T., Kunttu, J., Jasinevičius, G., Tuomasjukka, D. \& Lindner, M. Trade-offs in sustainability impacts of introducing cascade use of wood. Scand. J. For. Res. 32, 588-597 (2017).

26. Churkina, G. et al. Buildings as a global carbon sink. Nat. Sustain. 3, 269-276 (2020).

27. Max-Neef, M. in Real-Life Economics (eds Ekins, P. \& Max-Neef, M.) Ch. 7 (Routledge, 1992).

28. Doyal, L. \& Gough, I. A Theory of Human Need (Macmillan, 1991).

29. Bos-Brouwers, H., Langelaan, B. \& Sanders, J. Chances for biomass. Wageningen University UR https://edepot.wur.nl/248866 (2012).

30. Sandin, G. \& Peters, G. M. Environmental impact of textile reuse and recycling - a review. J. Clean. Prod. 184, 353-365 (2018).

31. Korhonen, J., Honkasalo, A. \& Seppälä, J. Circular economy: the concept and its limitations. Ecol. Econ. 143, 37-46 (2018).

32. Castro, M. B. G., Remmerswaal, J. A. M., Brezet, J. C. \& Reuter, M. A. Exergy losses during recycling and the resource efficiency of product systems. Resour. Conserv. Recycl. 52, 219-233 (2007).

33. Bergen, S. D., Bolton, S. M. \& Fridley, J. L. Design principles for ecological engineering. Ecol. Eng. 18, 201-210 (2001).

34. Vidal, O., Goffé, B. \& Arndt, N. Metals for a low-carbon society. Nat. Geosci. 6, 894-896 (2013)
35. Grandell, L. \& Höök, M. Assessing rare metal availability challenges for solar energy technologies. Sustainability 7, 11818-11837 (2015).

36. Kovacic, Z., Strand, R. \& Völker, T. The Circular Economy in Europe (Routledge, 2019)

37. Dammer, L. \& Essel, R. Quo Vadis, Cascading Use of Biomass? (nova Institute for Ecology and Innovation, 2015).

38. Cascading Use of Biomass: Opportunities and Obstacles in EU Policies 2013-2016 (Birdlife Europe \& European Environmental Bureau, 2014).

39. Zabaniotou, A. Redesigning a bioenergy sector in EU in the transition to circular waste-based bioeconomy: a multidisciplinary review. J. Clean. Prod. 177, 197-206 (2018).

40. Termeer, C. J. A. M. \& Metze, T. A. P. More than peanuts: transformation towards a circular economy through a small-wins governance framework. J. Clean. Prod. 240, 118272 (2019).

41. Velenturf, A. P. M. et al. Circular economy and the matter of integrated resources. Sci. Total Environ. 689, 963-969 (2019).

42. de Boer, I. J. M. \& Van Ittersum, M. K. Circularity in Agricultural Production (Wageningen University \& Research, 2018); https://edepot.wur.nl/470625

43. Van Eijk, F. Barriers \& Drivers Towards a Circular Economy (Acceleratio, 2015); https://www.circulairondernemen.nl/uploads/ e00e8643951aef8adde612123e824493.pdf

44. Teigiserova, D. A., Hamelin, L. \& Thomsen, M. Review of high-value food waste and food residues biorefineries with focus on unavoidable wastes from processing. Resour. Conserv. Recycl. 149, 413-426 (2019).

45. Gifford, R. \& Nilsson, A. Personal and social factors that influence pro-environmental concern and behaviour: a review. Int. J. Psychol. 49, 141-157 (2014)

46. Steg, L. \& Vlek, C. Encouraging pro-environmental behaviour: an integrative review and research agenda. J. Environ. Psychol. 29, 309-317 (2009).

47. Nyborg, K. et al. Social norms as solutions. Science 354, 42-43 (2016).

48. Kollmuss, A. \& Agyeman, J. Mind the gap: why do people act environmentally and what are the barriers to pro-environmental behavior? Environ. Educ. Res. 8, 239-260 (2002).

49. Rothgerber, H. Real men don't eat (vegetable) quiche: masculinity and the justification of meat consumption. Psychol. Men Masculin. 14, 363-375 (2013).

50. Shove, E., Watson, M. \& Spurling, N. Conceptualizing connections: energy demand, infrastructures and social practices. Eur. J. Soc. Theory 18, 274-287 (2015)

51. Barnes, S. J. Out of sight, out of mind: plastic waste exports, psychological distance and consumer plastic purchasing. Glob. Environ. Change 58, 101943 (2019).

52. Richter, B. Knowledge and perception of food waste among German consumers. J. Clean. Prod. 166, 641-648 (2017).

53. Schanes, K., Dobernig, K. \& Gözet, B. Food waste matters: a systematic review of household food waste practices and their policy implications. J. Clean. Prod. 182, 978-991 (2018).

54. Aschemann-Witzel, J., de Hooge, I., Amani, P., Bech-Larsen, T. \& Oostindjer, M. Consumer-related food waste: causes and potential for action. Sustainability 7, 6457-6477 (2015).

55. Priefer, C., Jörissen, J. \& Bräutigam, K. R. Food waste prevention in Europe: a cause-driven approach to identify the most relevant leverage points for action. Resour. Conserv. Recycl. 109, 155-165 (2016).

56. Ölander, F. \& Thøgersen, J. Informing versus nudging in environmental policy. J. Consum. Policy 37, 341-356 (2014).

57. Söderholm, P. Taxing virgin natural resources: lessons from aggregates taxation in Europe. Resour. Conserv. Recycl. 55, 911-922 (2011).

58. Growth Within: A Circular Economy Vision for a Competitive Europe (Ellen Macarthur Foundation, 2015); https://www.ellenmacarthurfoundation.org/ assets/downloads/publications/EllenMacArthurFoundation_Growth-Within July15.pdf

59. Spierling, S., Venkatachalam, V., Behnsen, H., Herrmann, C. \& Endres, H. Bioplastics and Circular Economy-Performance Indicators to Identify Optimal Pathways (Springer, 2019).

60. Van Zanten, H., Mollenhorst, H., Klootwijk, C. W., van Middelaar, C. E. \& de Boer, I. J. M. Global food supply: land use efficiency of livestock systems. Int. J. Life Cycle Assess. 21, 747-758 (2016).

61. Odegard, I., Croezen, H. \& Bergsma, G. Cascading of Biomass: 13 Solutions for a Sustainable Bio-based Economy-Making Better Choices for Use of Biomass Residues, By-products and Wastes (CE Delft, 2012).

62. Szarka, N., Wolfbauer, J. \& Bezama, A. A systems dynamics approach for supporting regional decisions on the energetic use of regional biomass residues. Waste Manage. Res. 36, 332-341 (2018).

63. Koppelmaki, K., Helenius, J. \& Schulte, R. P. O. Nested circularity in food systems: a Nordic case study on connecting biomass, nutrient and energy flows from field scale to continent. Resour. Conserv. Recycl. 164, 105218 (2021).

64. Mayer, A. L. Importing timber, exporting ecological impact. Science 308, 359-360 (2005). 
65. Mayer, A., Schaffartzik, A., Haas, W. \& Rojas-Sepúlveda, A. Patterns of Global Biomass Trade: Implications for Food Sovereignty and Socio-Environmental Conflicts (EJOLT, 2015).

66. Raworth, K. A doughnut for the Anthropocene: humanity's compass in the 21st century. Lancet Planet. Health 1, e48-e49 (2017).

67. O’Neill, D. W., Fanning, A. L., Lamb, W. F. \& Steinberger, J. K. A good life for all within planetary boundaries. Nat. Sustain. 1, 88-95 (2018).

\section{Acknowledgements}

This project has received funding from the European Union's Horizon 2020 Research and Innovation Programme under grant agreement no. 689669. The present work reflects only the authors' views and the funding agency cannot be held responsible for any use that may be made of the information it contains.

\section{Author contributions}

All authors wrote the paper. I.J.M.d.B. and M.K.v.I. conceptualized the principles. A.M., I.J.M.d.B., E.M.d.O. and R.R.-B. conceptualized and expanded the principles. A.M.,
I.J.M.d.B., E.M.d.O., H.H.E.v.Z. were responsible for visualization. A.M. prepared the original draft. E.M.d.O., R.R.-B., H.H.E.V.Z., T.A.P.M., C.J.A.M.T., M.K.v.I. and I.J.M.d.B, supervised, reviewed and edited.

\section{Competing interests}

The authors declare no competing interests.

\section{Additional information}

Correspondence should be addressed to I.J.M.d.B.

Peer review information Nature Food thanks Nick Holden, Trisha Toop and Bruce Dale for their contribution to the peer review of this work.

Reprints and permissions information is available at www.nature.com/reprints.

Publisher's note Springer Nature remains neutral with regard to jurisdictional claims in published maps and institutional affiliations.

(c) Springer Nature Limited 2021 